\title{
The antibiotic resistance proteome of Acinetobacter baumanii MDR isolate MMC\#4
}

\author{
Dana Marshall ${ }^{1 *}$, Jianan Dong ${ }^{2}$, Leon Dent ${ }^{3}$, Siddharth Pratap ${ }^{2}$ \\ From 11th Annual UT-ORNL-KBRIN Bioinformatics Summit 2012 \\ Louisville, KY, USA. 30 March - 1 April 2012
}

\section{Background}

Two hundred and forty-seven isolates of Acinetobacter baumanii (AB) were identified in the Nashville General Hospital at Meharry epidemiology database for a three year period. Of these isolates, $77 \%$ were multi-drug resistant (MRAB). Mechanical ventilation and multiple site recovery were associated with $M R A B$, and MRAB isolates were associated with increased mortality relative to sensitive $A B$ isolates $[1] . A B$ acquires resistance rapidly and the mechanisms are still being identified. Proteomic analysis can identify proteins that change in their expression levels in the presence of antibiotics, a possible mechanism of resistance for $\mathrm{AB}$. No proteome databases exist for this organism so antibiotic sensitivity and resistance pro- teomes were generated for MRAB bronchial wash isolate MMC\#4.

\section{Materials and methods}

AB MMC\#4 was grown in plain LB broth or LB broth supplemented with MIC50 concentrations of levofloxacin, tobramycin, gentamicin, cefotaxime and meropenem. Cell pellets were lysed and total protein run on an SDS-PAGE gel. Protein bands were excised and in-gel digested with trypsin. Resulting peptides were analyzed using a Thermo Finnigan LTQ ion trap mass spectrometer equipped with a 1-D nanoLC pump (Eksigent), Nanospray source (James A Hill Company), and Xcalibur 2.0 SR2 instrument control (Thermo Scientific). Peptides were separated on a

Table 1 Top 10 peptides identified more frequently in AB grown in the presence of antibiotic pressure when compared to $A B$ grown in the absence of antibiotic pressure.

\begin{tabular}{lll}
\hline Proteins & $\begin{array}{l}\text { Number of Hits Antibiotic } \\
\text { Treated }\end{array}$ & $\begin{array}{l}\text { Number of Hits No } \\
\text { Antibiotics }\end{array}$ \\
\hline $\begin{array}{l}\text { superoxide dismutase [Acinetobacter baumannii ACICU] } \\
\text { outer membrane protein, related peptidoglycan-associated (lipo)protein [Acinetobacter } \\
\text { baumannii ACICU] }\end{array}$ & 40 & 1 \\
$\begin{array}{l}\text { gluconate kinase [Acinetobacter baumannii ACICU] } \\
\text { electron transfer flavoprotein subunit alpha [Acinetobacter baumannii ACICU] }\end{array}$ & 9 & 2 \\
$\begin{array}{l}\text { Zn-dependent alcohol dehydrogenase, class III [Acinetobacter baumannii ACICU] } \\
\text { putative porin protein associated with imipenem resistance [Acinetobacter baumannii }\end{array}$ & 3 & 2 \\
$\begin{array}{l}\text { ACICU] } \\
\text { hypothetical protein ACICU_02436 [Acinetobacter baumannii ACICU] }\end{array}$ & 3 \\
$\begin{array}{l}\text { beta-lactamase [Acinetobacter baumannii ACICU] } \\
\text { malate dehydrogenase [Acinetobacter baumannii ACICU] }\end{array}$ & 76 & 2 \\
chaperonin GroEL [Acinetobacter baumannii ACICU] & 452 & 53 \\
\hline
\end{tabular}

\footnotetext{
* Correspondence: dmarshall@mmc.edu

'Department of Pathology, Anatomy and Cell Biology, Meharry Medical

College, Nashville, TN 37208, USA

Full list of author information is available at the end of the article
}

\section{() Biomed Central}

(C) 2012 Marshall et al; licensee BioMed Central Ltd. This is an Open Access article distributed under the terms of the Creative Commons Attribution License (http://creativecommons.org/licenses/by/2.0), which permits unrestricted use, distribution, and reproduction in any medium, provided the original work is properly cited. 
packed capillary tip (Polymicro Technologies, $50 \mu \mathrm{m}$ ID X $9 \mathrm{~cm})$ with $\mathrm{C} 18$ reverse phase resin $(5 \mu \mathrm{m}, 300 \AA$, Phenomenex). Tandem spectra were acquired using a data dependent scanning mode in which one full MS scan $(\mathrm{m} / \mathrm{z}$ 200-2000) was followed by 5 MS-MS scans. Tandem spectra were searched against the NCBI AB strain ACICU database using MryiMatch and IDPicker software. The search database was concatenated with the reverse sequences to determine false discovery rates. Proteins identified by less than two peptide spectral were eliminated (FDR $<5 \%$ ) and the output was filtered using IDPicker using a false positive ID threshold of $5 \%$. Protein reassembly from identified peptide sequences was done as described by Zhang et al. [2].

\section{Results and conclusions}

This analysis resulted in the identification of 125 highconfidence hits. Ten of these are presented in Table 1. Antibiotic stress resulted in increased detection of betalactamase (cefotaxime is a beta-lactam antibiotic) as well as several proteins associated with oxidative stress that have not previously been described in the context of MRAB resistance mechanisms. These results reinforce the utility of proteomes of antibiotic resistance for MRAB isolates in the identification of potential diagnostic and therapeutic targets, as well as resistance mechanisms, for this emerging pathogen.

\section{Acknowledgements}

This research was supported by The Meharry Translational Research Center (MeTRC) Grant Number U54RR026140-01 and The Research Centers in Minority Institutes (RCMI) Grant Number 3G12RR003032-24S1 from the National Center for Research Resources (NCRR), a component of the National Institutes of Health $(\mathrm{NIH})$. The research was also supported in part by Vanderbilt CTSA grant 1 UL1 RR024975 from the National Center for Research Resources, National Institutes of Health. Its contents are solely the responsibility of the authors and do not necessarily represent the official views of NCRR or $\mathrm{NIH}$.

\section{Author details}

${ }^{1}$ Department of Pathology, Anatomy and Cell Biology, Meharry Medical College, Nashville, TN 37208, USA. ${ }^{2}$ Bioinformatics and Proteomics Core, Meharry Medical College, Nashville, TN 37208, USA. ${ }^{3}$ Department of Surgery, Meharry Medical College, Nashville, TN 37208, USA.

Published: 31 July 2012

\section{References}

1. Dent $L L$, Marshall DR, Pratap S, Hulette RB: Multidrug resistant Acinetobacter baumanii: A descriptive study in a city hospital. BMC Infect Dis 2010, 10:196-202.

2. Zhang B, Chambers MC, Tabb DL: Proteomic parsimony through bipartite graph analysis improves accuracy and transparency. J Proteome Res 2007, 9:3549-3557.

doi:10.1186/1471-2105-13-S12-A20

Cite this article as: Marshall et al:: The antibiotic resistance proteome of Acinetobacter baumanii MDR isolate MMC\#4. BMC Bioinformatics 201213 (Suppl 12):A20

\section{Submit your next manuscript to BioMed Central and take full advantage of:}

- Convenient online submission

- Thorough peer review

- No space constraints or color figure charges

- Immediate publication on acceptance

- Inclusion in PubMed, CAS, Scopus and Google Scholar

- Research which is freely available for redistribution 